\title{
IMPACT OF ONLINE EDUCATION'S COMPATIBILITY ON STUDENT'S SATISFACTION IN UNIVERSITIES OF PAKISTAN BY USING TAM MODEL
}

\author{
Uzma Haleem \\ Research Scholar, \\ Department of Business Administration, UoK, \\ Sindh, Pakistan \\ Email: uzmakubs666@gmail.com \\ Muhammad Asim \\ Associate Professor, \\ Karachi University Bissness School, UoK, \\ Sindh, Pakistan \\ Email: masimku@hotmail.com

\section{Salman Manzoor} \\ Educational \& Literacy Department, Govt. of Sindh, \\ Sindh, Pakistan \\ Email: salmankubs@gmail.com
}

\begin{abstract}
The outbreak of COVID-19 has created a pandemic situation across every corner of the world. It has brought a great and unpredictable change in the lifestyle of the human race extended from one part to another part of the world. The significant unavoidable change in our lives is the shift from physical to online activities, especially in the education system. Moving from the physical education system to an online education system must not be easy for everyone. Particularly, in the territories with incompetent technology infrastructure or low-computer literacy rates like those of Pakistan. The current research work is an attempt to identify and investigate factors affecting students' satisfaction in the online learning environment in Pakistan. It is quantitative research and data was collected by distributing a well-structured questionnaire among students in different universities in Karachi. This data was run using Smart PLS3 software. Results for Average of Variation Explained (AVE) showed that the model used for the research is a quality model whereas path co-efficiencies have also supported the hypothesis I and 11. The outcomes revealed that technology compatibility and online learning self-efficacy both strengthen the online learning compatibility in Pakistan and thereby, significantly impact students' satisfaction.
\end{abstract}

\section{KEYWORDS}

LMS, Students' Satisfaction, Online Learning Compatibility, Online Learning SelfEfficacy, Online Learning Environment.

\section{INTRODUCTION}

Over the past decade, the greatest uplift has been observed in online learning popularity. 
PJER, Vol 4, Issue 2 (2021)

Impact of online... Substantial growth can be seen among students who prefer to go for online classes rather than attending any course class physically. Online learning is being considered as a convenient way for continuing education in any given circumstances especially for students who are unable to visit institutes or universities for any reason. However, there is also found a great proportion of the population who prefers face-to-face or traditional education over online learning setup. Moreover, a great variance is also found among the perceived learning outcomes among students. Some believe that there is no impact of face-to-face or traditional or online learning on learning outcomes of any course whereas some have a perception that advocates traditional learning setup for better learning outcomes. Such beliefs affect students' agreement in adopting online learning systems.

Although, when the COVID19 hit the world a pandemic situation was created that spread across the four corners of the world. COVID19 not only ceased social life worldwide but also banned the entire educational and economic activities in the world. During that sudden and uncertain condition, people were forced to stay at home and by the mid of the year almost all the business centers, shopping centers, schools, colleges, universities, and even grocery stores got shut down. Even hospitals were not opened for patients other than the corona virus-infected ones. Such a huge shutdown of almost all essential means of life it has almost impossible for people to even survives. However, the internet and smart technologies have contributed tremendously to keep life up. From social to economic, political to medical, education to healthcare, and other essentials for survival everything remained intact due to internet connectivity, computer, and smart technologies.

In the education sector, online learning has worked as a lifeline for the continuation of education for students across the globe. That's the reason a momentous sum of attention from academics has been heading for understanding and identifying those factors that may influence students' satisfaction, their perception regarding the quality of an internet-based or online learning environment, and their learning. The current research work is also a small contribution to that exertion. It is an attempt to investigate factors that influence students' satisfaction with online learning. The students are either graduates or master's students from different fields of studies and they belong to both the government and private universities in Karachi Pakistan. However, most of these students are from the business department both BBA and MBA. In universities of Karachi city, quite diverse social, ethnic, and regional student categories are found that can also affect students' body makeup. Thereby, this research work will easily showcase the students' satisfaction level for online learning at broad scope undertaking such a diverse group of students. This element of broad scope diversity is mostly overlooked by other researchers but this research will provide a fairly clear picture of facts. Through this research work is confined to the students studying in different universities of Karachi who are either in graduation or master but the factors used are globally recognized. Thereby, the findings of this research are broad in terms of their application at the global level.

The covid19 pandemic has obligatory pushed the entire education sector including both the learners and instructors to shift to the online learning setup though they were unfamiliar with it (Henriksen et al., 2020). Significant research work has been done on 
this area of research to elaborate student satisfaction, success elements of distance learning, acceptance of online learning or e-learning as well as the quality of online learning. However, a lesser amount of research work has been done in the context of Pakistan. Therefore, this research work aims to investigate an analysis across university students regarding their satisfaction in the online learning compatibility provided by their universities in Pakistan. The mediating factor perceived ease of use and perceived usefulness of TAM during this pandemic situation may effects students' satisfaction. Moreover, the influence of another independent variable will also investigate on student satisfaction.

\section{Scope of the Research}

The debate regarding the quality concerns for student satisfaction and their learning has lit up because of the suddenness of this transition. The research outcomes will contribute a lot to address students' satisfaction at broad scope as it has undertaken the key factors that have already proven to have made a significant impact on student's satisfaction in online learning. Therefore, the results of this research can be ideally generalized to the larger population.

\section{Conceptual Framework}

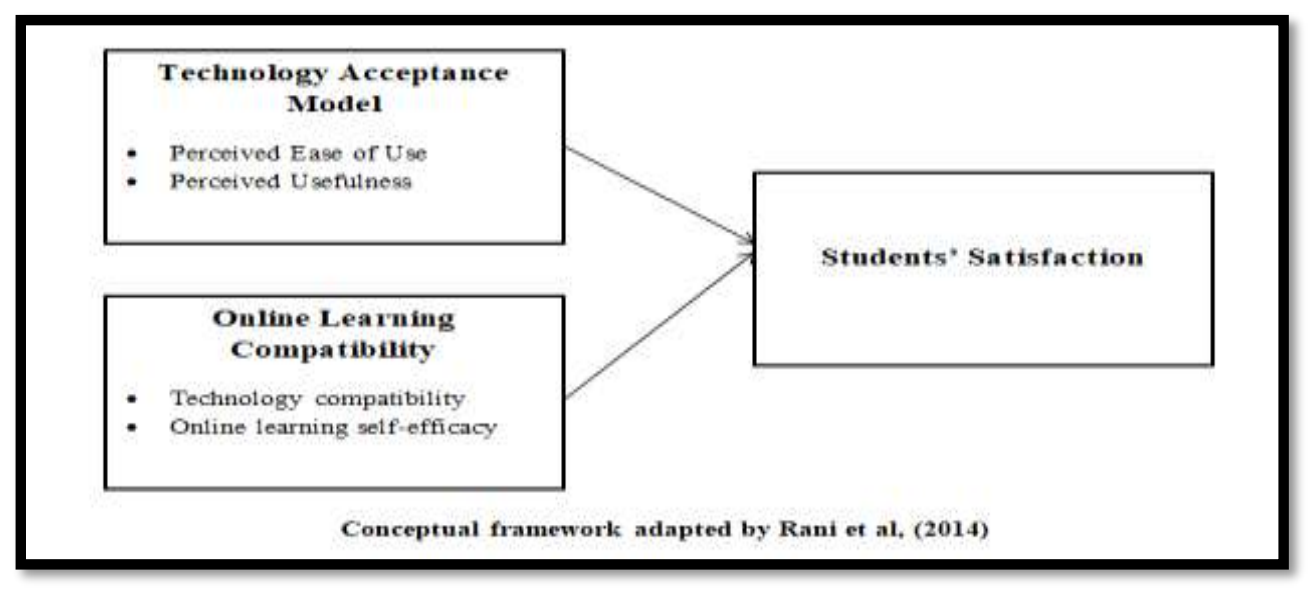

Figure 01: Conceptual Framework

\section{LITERATURE REVIEW}

The provision of COVID19 had created a pandemic situation worldwide that push almost all the educational institutes, colleges, and universities to move their traditional learning setup to online learning. However, no one was prepared to adopt that sudden transition. This move made by the education sector towards the adaptation of online learning has been referred to by many studies as a forceful yet important shift for enduring the entire learning process (Bao, 2020; Halim et al., 2020; Hodges et al., 2020; Zhu, 2020).

Students in Pakistan were not prepared psychologically to accept such a sudden shift, consequently to make a better understanding of students' satisfaction \& their perceived outcomes regarding this move will be examined in this piece of research work. 


\section{Online Learning Compatibility}

The term online learning is to describe an environment of electronic learning which is not like conventional learning, where peer learners are not physically present, and the freedom of space and time is provided to students. However, online learning turned out to learn more convenient and flexible (Manzoor et al., 2019). Similarly, it offers an alternative option to complete education especially for those who due to any reason are unable to physically attend the traditional classrooms. Electronic learning is a trend that has successfully emerged and acquired an outstanding position in the world of academics. Electronic learning often lies under the domain of distance education (Baber, 2020).

It is quite obvious that online learning would have numerous pros as well as corns simultaneously. In the modern age of technology, there is little key trepidation that directs the abrasion of online learners. This situation ultimately impedes the growth of online learning or courses. Lack of motivation or interest among students is the major factor that obstructs the progress of the environment of online learning, that's the reason it leads to the escalation of dropouts of students from any online course in the online learning setup (Ryan et al., 2016).

The eagerness among professionals, educationalists, researchers, and others have been evoking to recognize the ability of online learning in offering better academic achievements and results relative to traditional learning. The only way to get to know this is to evaluate students' motivation and their satisfaction related to online learning (Lockman and Schirmer, 2020). Several comparative studies and research work have been done to investigate which one of the two learning systems i.e., traditional or faceto-face learning method or the truly online learning or the blended or hybrid learning system is most effective (González-Gómez et al., 2016).

Some researches have proven that students in the environment of online learning have relatively better learning than those of traditional learning. The growing course completion rate, students' motivation, and their satisfaction levels to obtain knowledge at fullest from online courses are the factor that helps to observe this betterment in online learning among students. However, several other research works have also grasped the similar outcomes that better results can observe in online learning environments when compared with the traditional learning methods (Ryan et al., 2016).

Undoubtedly the trend of online learning is tremendously increasing in the current era of technology and innovation. Regardless of growing prominence in the academic world of online learning, there is found some researches has pointed out few limitations for online learning or has prioritized traditional or face-to-face learning over online learning (Ryan et al., 2016).

Those researches have shown a smaller proportion of success among online learners comparative to face-to-face learners. It is contingent on students' satisfaction, attendance, and motivation. However, other researchers have concluded that lower grades have been received by hybrid learners as compared to the face-to-face learners in examinations. The reason behind this outcome was that the face-to-face or traditional 
learners have physical or immediate access to the course instructors who assess them to direct or clarify any query or tough concepts whereas the online learners were unable to avail such help in the online learning environment. Furthermore, the significant role is played by course design/structure for acquiring better results as well as effects student satisfaction eventually (Powers et al., 2016).

\section{Online Learning Self-Efficacy}

When it comes to students' online learning and their satisfaction self-efficacy is the fundamental component of all. It is the level of a persons' confidence for performing a specific action, task, challenge, or activity. The same goes for students if they have a slight belief that they are incapable of achieving any particular task or results it means they will remain least bothered to even put a tiny effort towards the achievement of desire results/objectives. They will remain stubborn to even take the necessary steps towards the attainment of achievement. Conversely, high self-efficacy level among students won't hinder them to overcome any obstacle. However, it triggers students to take every obstacle as a challenge necessary to enhance various skills among them. The development of skills will not only enhance their performance but also lead to better learning and higher satisfaction. All these components are necessary for achieving profound results (Alqurashi, 2019).

Substantial research work has been done on students' self-efficacy factors in the context of the online learning environment of higher education. Mainly such researches stressed the technological aspect of the online learning environment including LMS (learning management system) self-efficacy, web-use self-efficacy, internet self-efficacy, and computer/laptop self- efficacy. Moreover, when it comes to student satisfaction internet self-efficacy has been found to have no significant effect. It has nothing to do with course performance. In the e-learning system perceived self-efficacy failed to show perceived satisfaction in terms of the relationship. Similarly, computer self-efficacy has been used in numerous researches but unfortunately, neither the internet nor computer self-efficacy has shown any significant outcomes in the e- learning system or environment. These factors have no significant relationship with student satisfaction in the e-learning environment (Alqurashi, 2016).

Therefore researchers now focus more on self-efficacy than that of technology when evaluating the relationship between perceived student satisfaction and self-efficacy. However in some researches, computer self-efficacy has shown a positive impact on student satisfaction $\mathrm{s}$ well but it is more functional to work on self-efficacy than technology efficacy (Alqurashi, 2019).

Online self-efficacy is the resilient predictor for determining student satisfaction. Furthermore, along with online self-efficacy, the self-efficacy level for interacting with course instructor has a tremendous effect on student satisfaction in online learning systems. Consequently, self-efficacy for online learning has a significant and positive relationship with student satisfaction in online courses with the self-paced facility (Alqurashi, 2016).

With the advancement of technology, the self-efficacy level among students for technology has been dramatically improved. Today the students in educational institutes 
like colleges and universities have become more competent in performing almost all the web or internet based activities confidently. That's the reason the level of technology self-efficacy has become relatively less predictive for examining students' perceived satisfaction or learning experience in the e-learning environment (Alqurashi, 2019).

Although for learning in an e-learning system a student must need to have good command over technology skills it is impossible to overlook the fastest growth in technology and the pace of adaptation among its potential users. In this era of innovation and advanced technology, students are more exposed to the latest technologies. Now they can easily access to advanced technologies than ever before. Students today also vary in regards to confidence and comfort level in terms of fluency and capabilities with advanced technology. Their attitudes toward the adaptation of technology have also evolved with the evolution of advanced technology. The willingness among students to interact and use technology seemed to have increased with time. They are more willing to communicate, interact, and study using technology. IT shows that the researchers are required to focus more on students' confidence and their abilities to learn, compete, perform and engage with an online course rather than their self- efficacy with technology (Alqurashi, 2016).

Thereby, the students' satisfaction was found to have made a tremendous impact on the success level of students who enrolled in that online course. The more the students satisfied with the online course they have enrolled in the more good performance they will show in their academics. So, it is essential to achieve students' satisfaction if the colleges or universities are seeking greater academic performance among students that's why more attention should be pay to course content of online courses being offered to students (Chakravorti, 2019).

The course instructor should provide a comprehensive road map featuring the expectations for course assignments, the resources students require to complete the course, due dates, rubrics assessment, guidelines, and should facilitate students to sustain learning (Gray and DiLoreto, 2016).

The infrastructure of an online course should be clear in terms of determining learning objectives that students will obtain, user-friendly, and logically organized. Since the beginning, the objectives of each online course should be clear and well-defined. Similarly, these learning objectives must be communicated to the students for greater academic results (Gray and DiLoreto, 2016).

Teachers or course instructors must have enough proficiency to cultivate such a structure of online class that can influence social interaction among students, and upholds arduous academic standards, whereas encouraging autonomous learning skills. In case of the absence of technological skills in instructors/teachers to establish engaging courses, the designers, of course, should consider facilitating them with some additional support, guidance, and training (Jaggars \& Xu, 2016).

The perception of students regarding the general usability of any specific online course is closely correlated to their learning and satisfaction. Thereby, the more logical and organized the layout of an online course, the more the students will get satisfied with 
what they are learning in that online course (Jaggars \& Xu, 2016).

\section{Technology Compatibility}

The ways any individual, institute, university, and firm exchange information and interact change the information technology (IT). It is the change that has made a huge investment of around $\$ 3.5$ trillion by 2017 on a global scale. The significant increase in the trend of delivering extended online course content over the internet has changed the approach of interacting and teaching students. In the current digital environment management, scholars and educational organizations must define the IT resources that must be used in online classes. Similarly, the way should be determined to help institutes and instructors about how they can leverage information technologies to enhance students learning and to acquire student satisfaction (Rueda et al., 2017).

Just like physical classes where the course instructor available in the class, the presence of capable instructors is also required during online classes. The most critical aspect of capability is the capacity to utilize technologies for learning purpose, to facilitate the smooth provision of online course content as well as to encourage strong interactions among participants. To extend support for online social interaction and online learning activities it is imperious to utilize learning technologies. Such ad the utilization of videoaudio lectures in every online class is found to have lessened the time required for learning as well as has created an optimistic impact on grades of students (Chakravorti, 2019).

The convenience online courses offer is the main reason for the admiration of this advanced learning domain. However, the physical unavailability of course instructor in an online class has a negative impact on students. This unavailability upsurges the probabilities for inefficiencies and dysfunction. Although effectively utilizing a couple of learning technologies facilitate universities not only to deliver information accurately and timely but also contribute significantly to eliminating the probabilities for inefficiencies and dysfunction. Furthermore, through incorporating effective learning technologies greater flexibility can also be provided to students and course instructors (Chakravorti, 2019).

A number of tools and software are available to create an efficient environment for online learning. Utilizing these tools and software the course instructor and teachers can gather crucial data about students and their participation in a specific online course. Similarly, these technological tools assist instructors to easily review data of students' log-in, views for course content, minutes they spend online, assessments of all the learning modules, and information provided by students themselves using, discussions, surveys, reflections as well as various other seminal tools (Gray and DiLoreto, 2016).

The evaluation of academic challenge levels is quite imperative for every online course. This evaluation should be grounded on the time invested, collaborative and active learning, effort exerted, and prospects for interacting with students and faculty and stirring students' educational experiences during an online course. Such assessments can only be attained by formally or informally surveying students in an online course and then by investigating the results obtained through those surveys. The results extracted from this evaluation process will assist the course instructor \& the 
management of the institute or university to enhance the instructional practices. Thereby, better educational services can be designed and offered to the students in the future (Gray and DiLoreto, 2016).

\section{Technology Acceptance Model}

Other than capabilities and efforts that an instructor makes in developing an easy to comprehend yet challenging content for an online course, in the utilization of learning technologies to construct an effective structure for the online course and in providing technological facilities for interaction, the major constituent of success for each online course is the acceptance among students and utilization of the provided learning management system (Salloum, and Shaalan, 2018).

TAM (technology acceptance model) offers a thoughtful user acceptance for any technology and use of that technology grounded on a person's internal beliefs. Perceived ease of use and perceived usefulness are two key determinants of this model that influences actual usage and behavioral intentions. Substantial evidence provided by researches that perceived usefulness in TAM is the greater interpreter of actual usage of systems comparatively to TAM's perceived ease of use (Ibrahim et al., 2017).

However, both of these factors are correlated where the perceived ease of use is found to have made a strong impact on the factor perceived usefulness. An experience that a person has with technology matters a lot for acceptance of that technology. It has been found through researches that experience using any technology moderates positively the influence of perceived ease of use factor on the perceived usefulness factor. Moreover, it has also positively influenced the perceived usefulness factor on the intent to use (Hussein, 2017).

TAM has somber associations with the technological features of any online course structure and design which affect satisfaction and learning. First of all shape the perception about technology. Make the user believe that this technology or system is quite easy to use. If a firm belief in ease of use is created the user will be more likely to put greater input overcoming any difficulty. Moreover, the actual yet positive experience of using technology along with the perceived ease of use can help in shaping users' overall perception of the usefulness of technology for learning any course, establish an affinity between the preferred learning style and the technology as well as it will further encourage users to endure the usage of technology (Turan and Cetintas, 2020).

Researches based on TAM in the context of education or e-learning has proven that comfort and familiarity with e-learning and computer technology impact users' performance positively in any online class. Such improved performance is probably come into being via enhanced satisfaction and learning. TAM-based researches generally used to make a more detailed understanding of acceptance of technology, students' satisfaction, and their learning at an extra granular level. First, it split technology into three key features including LMS (learning management system), internet, and computer. Then, it calculates the self-efficacies of users for each of those features (Al-Rahmi et al., 2019). 
A mixed type of impact has been found for satisfaction and learning. Some researchers concluded that prior experience and computer self-efficacy of users have an immense impact on learning only. However, others claimed to have observed a strong influence of users' computer self-efficacy on their satisfaction level instead of learning. Moreover, there are also some researches that showed a weak yet momentous relationship between student satisfaction and internet efficacy (Chakravorti, 2019).

On the basis of such findings, it can be claimed that students with higher internet and computer self-efficacy usually have greater experience in the online environment. This experience facilitates them in the establishment of higher capabilities of locating and searching for information. Such capabilities in return impact their performance and satisfaction (Chakravorti, 2019).

Self-efficacy in LMS although is found to have created no noticeable on online learners' performance. For the effectiveness of any online learning mechanism, it is imperative that both the teachers and learners learn first how effectively the technology can be used to boost learning approaches then strive for achieving possible benefits it may serve (Chakravorti, 2019).

\section{Students' Satisfaction}

Student satisfaction can be referred to as the blessedness and satisfaction of students related to either various or some aspects of any service they receive. Thereby, satisfaction is an element that is affected directly by different elements of that particular service. In the context of the education system particularly online learning, many researchers have investigated and identified various factors influencing student satisfaction. Feedback, activities, interaction among students and instructors in face-toface and online classes, teacher and student behaviors, technical and instructional support, materials, technological features, online discussion, demographic characteristics, skills, knowledge, and self-efficacy can be considered as the most dominant of such factors. Satisfaction level among students for any learning activity or online course is the principle for developing an efficient course structure and for making a better understanding of that online course's efficiency (Yilmaz, 2017).

Student satisfaction has now become the central point because of growing competition among educational institutes, universities, and colleges that directed towards customercentric business models. Researches investigating the determinants of student satisfaction within the context of online learning are generally recognized factors like course content, interaction, perceived usefulness, computer self-efficacy, and selfregulation (Parahoo et al., 2016).

Moreover, many other pieces of research have concluded that interaction among students and their classmates, staff, or faculty as well as the reputation of the educational institute had an immense influence on students' satisfaction. However, these are findings are quite a mix in terms of the effect of interaction on students' satisfaction.

Furthermore, content structure, system functionality and compatibility, and computer self-efficacy are found to have a positive impact on students' perceived learning and performance. Additionally, interaction, application-specific computer self-efficacy, 
social presence, and perceived usefulness had a positive influence on students' satisfaction with online courses (Landrum et al., 2020).

Alqurashi (2016) has concluded that students' satisfaction in an online learning system is positively affected by computer self-efficacy, interactive learning environment, and quality of its interaction, self-efficacy, ease of use, and students' perceived ease of usefulness. However, Cochran et al., (2016) have identified and categorized factors influencing students' satisfaction into faculty, student-driven factors, and course. Apart from that course content, course structure/ design, teacher/student interaction, and course clarity were reported to have a positive impact related to students' satisfaction (Li et al., 2016; Price et al., 2016). Some researchers have addressed this area of research to measure students' level of satisfaction in both the online and traditional environments. Gray and DiLoreto (2016), discussed that students mostly evaluate their course instructor and courses as satisfactory one when they supposed that they have been encouraged or facilitated well in their learning, effectively communicated by their course instructors, their online course is effectively organized, they have respected by instructors and institutes, their course instructors have shown great importance in their progress and learning as well as their work has been evaluated accurately.

Student satisfaction and their perceived learning collectively symbolize enhanced understanding of the success of online success (Gray and DiLoreto, 2016). The successful experience for online learning/courses is highly correlated to students' satisfaction whereas the perceived learning among students is an upright determinant of student satisfaction in any online learning setup. The perceived learning is also discovered to have contributed significantly towards students' satisfaction. Moreover, it has a positive impact on the online learning environment as well (Ikhsan et al., 2019).

\section{RESEARCH OBJECTIVE}

1. The current research has an objective to identify the impact of online learning compatibility on students' satisfaction. However, technology compatibility, and online learning self-efficacy have been used to measure online compatibility in Pakistan.

\section{RESEARCH QUESTIONS}

1. Does the compatibility of the LMS with the student's learning method influence student satisfaction in online courses?

2. Does online learning self-efficacy affect student satisfaction in online learning?

\section{RESEARCH HYPOTHESIS}

1. Technology compatibility has a significant influence on students' satisfaction.

2. Online learning compatibility has an immense effect on students' satisfaction.

\section{RESEARCH METHODOLOGY}

Data is collected to extract results from 100 students of the university including both the graduate and master level students from a different area of study. All these students are enrolled in online learning programs due to COVID19. These students are previously enrolled in traditional learning setup and are mostly professionals. The students in the sample are from different social, demographic, and income classes that may also affect their satisfaction level for online learning. 
Student satisfaction is the dependent variable whereas there are three independent variables including online learning self-efficacy, and technology compatibility that contribute to online learning compatibility. All these variables are adopted from previous research work and have multiple items for each variable. A five-point Likert scale is used as the instrument for measuring responses except for the number of online classes taken and age. The instrument used for measuring and analyzing responses is Smart PLS3 software.

Data was collected by distributing questionnaires in person and over Google among students of graduation and master. The responses from students were recorded on a Google spreadsheet automatically then transported into excel spreadsheets. Then the collected data is used for analyzing the results.

The research is a quantitative research and the data gathered through a questionnaire has been run over software known as Smart PLS3. After running the data over this software following are the observations that have been extracted to drive out concrete results for the current research work.

\section{FINDINGS \& RESULTS}

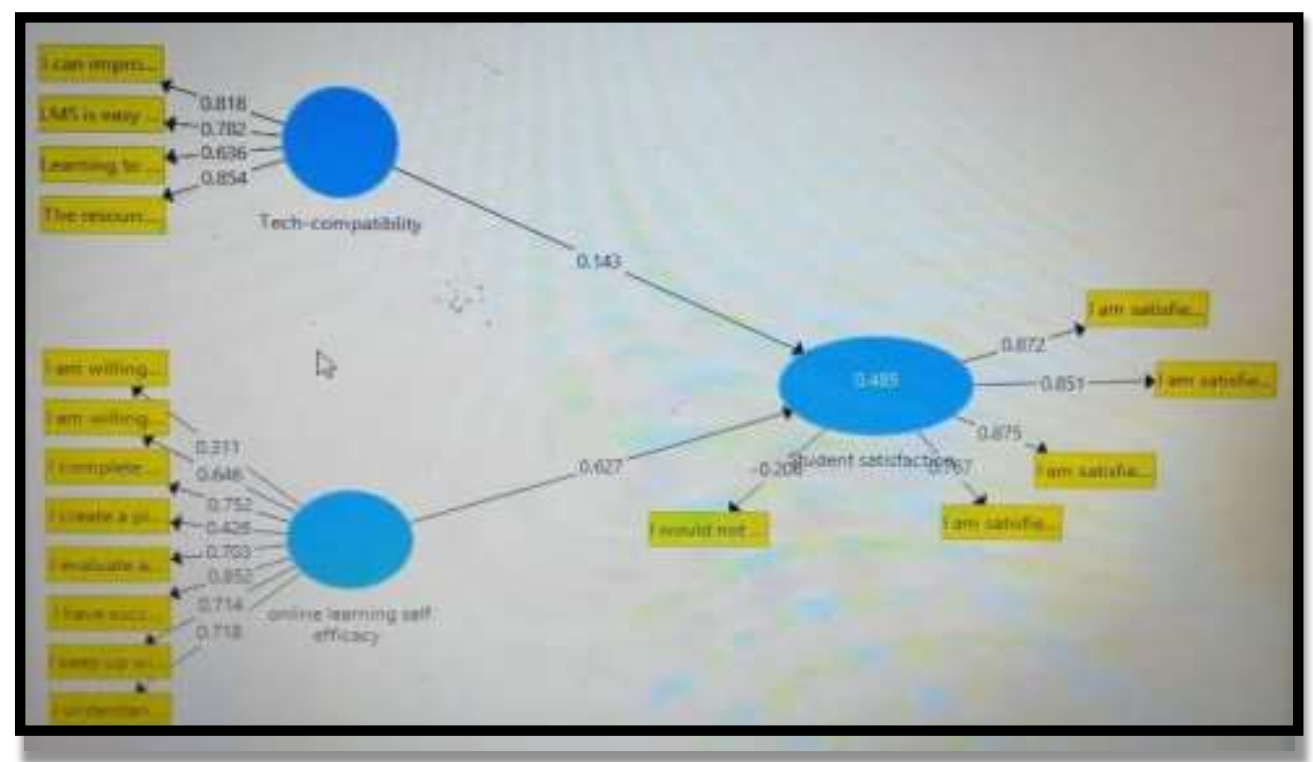

Figure 02: Model Diagram after running data over Smart PLS3 software

Table 01: Average Of Variation

\begin{tabular}{lclll}
\hline & AVE & $\begin{array}{l}\text { Composite } \\
\text { Reliability }\end{array}$ & $\begin{array}{l}\text { R } \\
\text { Square }\end{array}$ & $\begin{array}{l}\text { Cronbach } \\
\text { Alpha }\end{array}$ \\
\hline $\begin{array}{l}\text { Student } \\
\text { satisfaction }\end{array}$ & 0.577 & 0.825 & 0.845 & 0.699 \\
$\begin{array}{l}\text { Technology } \\
\text { compatibility }\end{array}$ & 0.604 & 0.858 & - & 0.791
\end{tabular}




\begin{tabular}{lllll}
\hline $\begin{array}{l}\text { Online } \\
\text { learning } \\
\text { self-efficacy }\end{array}$ & 0.438 & 0.854 & - & 0.816 \\
\hline
\end{tabular}

This table determines that the AVE of all variables ranges $0.4-0.6$ which means the model suggested in this research is a quality model.

Table 02: Path Co-Efficiencies

\begin{tabular}{lcll}
\hline & $\begin{array}{l}\text { Student } \\
\text { Satisfaction }\end{array}$ & $\begin{array}{l}\text { Technology } \\
\text { Compatibility }\end{array}$ & $\begin{array}{l}\text { Online Learning } \\
\text { Self-Efficacy }\end{array}$ \\
\hline $\begin{array}{l}\text { Student satisfaction } \\
\text { Technology } \\
\text { compatibility }\end{array}$ & 0.143 & & \\
$\begin{array}{l}\text { Online learning self- } \\
\text { efficacy }\end{array}$ & 0.627 & & \\
\hline
\end{tabular}

The above table shows that technology compatibility has a direct impact of 0.143 on student satisfaction whereas online learning self-efficacy demonstrated a direct impact of 0.627 on it. Thereby, it has proven the hypothesis I and II thus we have accepted both the hypothesis.

\section{DISCUSSION}

The key objective of this research work is to identify and establish an improved understanding of the factors that influence student satisfaction in the online learning environment provided by different universities in Karachi Pakistan. After thoroughly analyzing the data obtained through the smart PLS3 software program it has been found that technology compatibility and online learning self-efficacy both have a significant impact on students' satisfaction in the online learning environment in Pakistan. The outcomes received acknowledge the significance of technology compatibility as well as a students' online learning self-efficacy for enhancing the online learning compatibility. This online learning compatibility has a direct impact on students' satisfaction in an online learning environment.

The values of the average variation explained (AVE) for each variable strongly support that the model used in this research work is high in quality. It means the model designed by the researcher for carrying out this piece of research was truly appropriate for the successful execution of the research. Moreover, the path efficiencies measure by using the Smart PLS3 software program for each variable supports both the research's hypothesis. Thereby, both technology compatibility and online learning self-efficacy are proven to be the most crucial factors for enhancing online learning compatibility. These results move along with the majority of research studies done in past.

\section{RECOMMENDATIONS}

The study has involved students from different universities, the field of studies, degree programs, age group, and gender. Regardless of great similarities, students may show variation in responses across different localities, social classes, universities, and regions 
when it comes to implying international or regional students' satisfaction level in the online learning environment. Therefore the finding of this research work is applicable provided the same student body and university's infrastructure when investigating the factors affecting student's satisfaction in an online learning environment.

Further research work is highly recommended to not only identify more variables that might play a key role in satisfying students enrolled in any online course. Although the current research work has produced evidence that strengthens the significance of technology compatibility and online learning self-efficacy for achieving students' satisfaction. This research work can be used as a base for carrying out further research work however for acquiring outcomes that can be applied at a mass level more factors must be included in the research.

The current research work should be considered in sub-discipline as a knowledge base. The variables undertaken in the research work to investigate what affects students' satisfaction in the online learning environment have shown a small proportion of impact. However, various other factors should also be considered while investigating this area of research. Similarly, the pandemic due to COVID-19 has also hindered the researcher in reaching out to students in different universities and departments therefore the sample size of the research is kept small up to 100 respondents. Moreover, the Smart PLS3 software program also allowed the researcher to run the data of responses only for 100 respondents not above. Thus it limited the researcher to conduct the research on a broad span.

\section{REFERENCES}

Alqurashi, E. (2016). Self-efficacy in online learning environments: A literature review. Contemporary Issues in Education Research (CIER), 9(1), 45-52.

Alqurashi, E. (2019). Predicting student satisfaction and perceived learning within online learning environments. Distance Education, 40(1), 133-148.

Al-Rahmi, W. M., Yahaya, N., Aldraiweesh, A. A., Alamri, M. M., Aljarboa, N. A., Alturki, U., \& Aljeraiwi, A. A. (2019). Integrating technology acceptance model with innovation diffusion theory: An empirical investigation on students' intention to use E-learning systems. IEEE Access, 7, 26797-26809.

Baber, H. (2020). Determinants of students' perceived learning outcome and satisfaction in online learning during the pandemic of COVID-19. Journal of Education and ELearning Research, 7(3), 285-292.

Bao, W. (2020). COVID-19 and online teaching in higher education: A case study of Peking University. Human Behavior and Emerging Technologies, 2(2), 113-115.

Chakravorti, S. (2019). Student Satisfaction and Learning in Online Classes: The Case of a US Midwestern University.

Cochran, J. D., Baker, H. M., Benson, D., \& Rhea, W. (2016). Business student perceptions of online learning: Using focus groups for richer understanding of student perspectives. Organization Management Journal, 13(3), 149-166.

González-Gómez, D., Jeong, J. S., \& Rodríguez, D. A. (2016). Performance and perception in the flipped learning model: an initial approach to evaluate the effectiveness of a new teaching methodology in a general science classroom. Journal of Science Education and Technology, 25(3), 450-459.

Gray, J. A., \& DiLoreto, M. (2016). The effects of student engagement, student satisfaction, 
and perceived learning in online learning environments. International Journal of Educational Leadership Preparation, 11(1), n1.

Halim, M. S. A. A., Hashim, H., \& Yunus, M. M. (2020). Pupils' Motivation and Perceptions on ESL Lessons through Online Quiz-Games. Journal of Education and E-Learning Research, 7(3), 229-234.

Henriksen, D., Creely, E., \& Henderson, M. (2020). Folk Pedagogies for Teacher ransitions: Approaches to Synchronous Online Learning in the Wake of COVID-19. Journal of Technology and Teacher Education, 28(2), 201-209.

Hodges, C., Moore, S., Lockee, B., Trust, T., \& Bond, A. (2020). The difference between Emergency remote teaching and online learning. Educause Review, 27.

Hussein, Z. (2017). Leading to intention: The role of attitude in relation to technology acceptance model in e-learning. Procedia Computer Science, 105, 159-164.

Ibrahim, R., Leng, N. S., Yusoff, R. C. M., Samy, G. N., Masrom, S., \& Rizman, Z. I. (2017). E-learning acceptance based on technology acceptance model (TAM). Journal of Fundamental and Applied Sciences, 9(4S), 871-889.

Ikhsan, R. B., Saraswati, L. A., Muchardie, B. G., \& Susilo, A. (2019, October). The Determinants of Students' Perceived Learning Outcomes and Satisfaction in BINUS Online Learning. In 2019 5th International Conference on New Media Studies (CONMEDIA) (pp. 68-73). IEEE.

Jaggars, S. S., \& Xu, D. (2016). How do online course design features influence student performance? Computers \& Education, 95, 270-284.

Landrum, B., Bannister, J., Garza, G., \& Rhame, S. (2020). A class of one: Students' satisfaction with online learning. Journal of Education for Business, 1-7.

Li, N., Marsh, V., \& Rienties, B. (2016). Modelling and managing learner satisfaction: Use of learner feedback to enhance blended and online learning experience. Decision Sciences Journal of Innovative Education, 14(2), 216-242.

Lockman, A. S., \& Schirmer, B. R. (2020). Online Instruction in Higher Education: Promising, Research-Based, and Evidence-Based Practices. Journal of Education and e-Learning Research, 7(2), 130-152.

Granitz, N. A., Koernig, S. K., \& Harich, K. R. (2009). Now it's personal: Antecedents and outcomes of rapport between business faculty and their students. Journal of Marketing Education, 31(1), 52-65.

Powers, K. L., Brooks, P. J., Galazyn, M., \& Donnelly, S. (2016). Testing the efficacy of MyPsychLab to replace traditional instruction in a hybrid course. Psychology Learning \& Teaching, 15(1), 6-30.

Price, R. A., Arthur, T. Y., \& Pauli, K. P. (2016). A Comparison of Factors Affecting Student Performance and Satisfaction in Online, Hybrid and Traditional Courses. Business Education Innovation Journal, 8(2).

Rani, N. S. A., Suradi, Z. U. R. I. N. A. H., \& Yusoff, N. H. (2014). An analysis of technology acceptance model, learning management system attributes, e- satisfaction, and eretention. International Review of Management and Business Research, 3(4), 19841996.

Rueda, L., Benitez, J., \& Braojos, J. (2017). From traditional education technologies to student satisfaction in Management education: A theory of the role of social media applications. Information \& Management, 54(8), 1059-1071.

Ryan, S., Kaufman, J., Greenhouse, J., She, R., \& Shi, J. (2016). The effectiveness of blended online learning courses at the community college level. Community College Journal of Research and Practice, 40(4), 285-298.

Salloum, S. A. S., \& Shaalan, K. (2018). Investigating students' acceptance of E-learning system in Higher Educational Environments in the UAE: Applying the Extended Technology Acceptance Model (TAM). The British University in Dubai.

Manzoor, S., Asim, M., \& Ahmad, B. (2019). Stimulating Unceremonious Mobile Learning: 
An Empirical Study of Business Students of Sindh, Pakistan. Global Management Journal for Academic \& Corporate Studies, 9(2), 1-14.

Turan, Z., \& Cetintas, H. B. (2020). Investigating university students' adoption of video lessons. Open Learning: The Journal of Open, Distance and e-Learning, 35(2), 122-139.

Yilmaz, R. (2017). Exploring the role of e-learning readiness on student satisfaction and motivation in flipped classroom. Computers in Human Behavior, 70, 251-260.

Zhu, X., Chen, B., Avadhanam, R. M., Shui, H., \& Zhang, R. Z. (2020). Reading and connecting: using social annotation in online classes. Information and Learning Sciences. 